\title{
Strain Mapping and Damage Tracking in Carbon Fiber Reinforced Epoxy Composites during Dynamic Bending Until Fracture with Quantum Resistive Sensors in Array
}

\author{
Antoine Lemartinel ${ }^{1,2}$, Mickaël Castro ${ }^{2, * \mathbb{D}}$, Olivier Fouché ${ }^{1}$, Julio-César De Luca ${ }^{1}$ (D) and Jean-François Feller ${ }^{2} \mathbb{D}$ \\ 1 Institut de Recherche Technologique Jules Verne, 44340 Bouguenais, France; \\ antoine.lemartinel@gmail.com (A.L.); olivier.fouche@irt-jules-verne.fr (O.F.); \\ julio-cesar.de-luca@irt-jules-verne.fr (J.-C.D.L.) \\ 2 Smart Plastics Group, Université de Bretagne Sud, UMR CNRS 6027, IRDL, 56100 Lorient, France; \\ jean-francois.feller@univ-ubs.fr \\ * Correspondence: mickael.castro@univ-ubs.fr
}

check for updates

Citation: Lemartinel, A.; Castro, M.; Fouché, O.; De Luca, J.-C.; Feller, J.-F. Strain Mapping and Damage

Tracking in Carbon Fiber Reinforced Epoxy Composites during Dynamic Bending Until Fracture with Quantum Resistive Sensors in Array. J. Compos. Sci. 2021, 5, 60. https://doi.org/10.3390/jcs5020060

Academic Editor: Jiadeng Zhu

Received: 18 January 2021

Accepted: 18 February 2021

Published: 20 February 2021

Publisher's Note: MDPI stays neutral with regard to jurisdictional claims in published maps and institutional affiliations.

Copyright: (c) 2021 by the authors. Licensee MDPI, Basel, Switzerland. This article is an open access article distributed under the terms and conditions of the Creative Commons Attribution (CC BY) license (https:/ / creativecommons.org/licenses/by/ $4.0 /)$.

\begin{abstract}
The sustained development of wind energies requires a dramatic rising of turbine blade size especially for their off-shore implantation, which requires as well composite materials with higher performances. In this context, the monitoring of the health of these structures appears essential to decrease maintenance costs, and produce a cheaper kwh. Thus, the input of quantum resistive sensors (QRS) arrays, to monitor the strain gradient in area of interest and anticipate damage in the core of composite structures, without compromising their mechanical properties, sounds promising. QRS are nanostructured strain and damage sensors, transducing strain at the nanoscale into a macroscopic resistive signal for a consumption of only some $\mu \mathrm{W}$. QRS can be positioned on the surface or in the core of the composite material between plies, and this homogeneously as they are made of the same resin as the composite. The embedded QRS had a gauge factor of 3, which was found more than enough to follow the strain from $0.01 \%$ to $1.4 \%$ at the final failure. The spatial deployment of four QRS in array made possible for the first time the experimental visualization of a strain field comparable to the numerical simulation. QRS proved also to be able to memorize damage accumulation within the sample and thus could be used to attest the mechanical history of composites.
\end{abstract}

Keywords: structural health monitoring (SHM); carbon nanotubes (CNT); quantum piezo-resistive sensor (QRS); in situ measurements; smart materials; embedded sensors

\section{Introduction}

Recently, the need to reduce the carbon emissions resulting from the use of fossil fuels makes it necessary to strongly develop renewable energies worldwide [1]. In 2015, COP 21 agreed to achieve a balance between carbon emissions and removals by sinks of greenhouse gases [2]. In the case of wind energy, the size of wind turbine is continuously increased to provide more energy per unit. In the early 1980s, the length of the blade was $7.5 \mathrm{~m}$; today it is $80 \mathrm{~m}$, and could exceed $100 \mathrm{~m}$ in 2030 [3,4]. To ensure a continuous and powerful wind flow, the turbines are designed to withstand a harsher environment, and are therefore located further away from the coast. The lifetime of these structures should also be improved, with a view to less systematic maintenance. Nowadays, composites materials are essential for the manufacture of wind turbines blades, usually made of glass fibers assembled with an epoxy matrix. However, composites are anisotropic or orthotropic materials, and their failure is a complex combination of various mechanisms such as matrix cracking, delamination, fiber breakage, or interfacial debonding [5]. As a result, the initiation and propagation of damage remains difficult to predict. Detection of damage along with undergone strain could lead to better prediction of the ultimate failure of the structure, thereby reducing maintenance costs. For instance, of the current total cost 
of onshore wind turbines, which amounts to more than $1 \mathrm{M} € / \mathrm{MW}$, about $10 \%$ is due to maintenance [6], and the shift to offshore plants could increase this cost to nearly $30 \%[7,8]$. Within this frame, a Structural Health Monitoring system (SHM), which would provide clues on the state of health of the material, comes out like a very interesting tool [9-12]. SHM systems have multiple objectives, such as enabling optimal use of the structure, minimizing downtime and avoiding catastrophic failures. They should also help to replace scheduled and periodic maintenance with performance-based inspections; as well as reduce human intervention for less labor, fewer human errors, and thus greater reliability.

Over the past decades, various conventional techniques have been developed to detect and measure the deformation or initiation of cracks and their propagation through the structure being monitored. These techniques involve primarily the use of metal strain gauges, piezo-resistive sensors, optical fiber sensors, and acoustic sensors. In a complex structure such as a wind turbine blade, the maximum stresses are localized in defined areas, due to the shape of the structure [13]. Structural monitoring of these areas is critical to detect the degradation in the state of the structure. Therefore, the SHM device should provide details of the in situ state in order to prevent failure of the structure, since some parts of the structure, such as the spar cap in the case of windmills, may be several centimeters thick [14]. Ideally the location of strain and damage in the selected area would be done by volume mapping. To date, few of the existing monitoring techniques proved capable to perform internal and external measurements of strain and damage detection. A recent study by Holmes et al. [15] has addressed this issue based on fiber optic technology, specifically machined to reduce their thickness and providing through-thickness strain monitoring of advanced composites. However, the handling of such sensors remains tricky.

This challenging task has recently attracted the interest of the research community, especially since the discovery of new nanoparticles such as carbon nanotubes [16,17]. As a result, conductive nanocomposites obtained by dispersing these nanofillers in a polymer matrix have led to the development of promising self-sensing materials [18-27]. Thanks to their unique mechanical [25,28-30], thermal [31-33] and electrical properties [25,34,35], carbon nanotubes (CNT) are interesting candidates for the development of nanocomposites. Since the nanofillers can be structured into a 3D conductive network within the insulating polymer matrix, changes in the resistance of this network in response to mechanical solicitations can be used to detect and measure the deformation and possible damages to the composite $[19,27,29,36-41]$. Furthermore, the use of such smart materials leads to a perfect match between the durability of the host structure and the nanocomposite used to sense its state of health. Nevertheless, out of these different strategies to structure percolated networks into polymer matrices, one is particularly seducing, it consists to introduce locally a patch of matrix-CNT nanocomposite instead of dispersing CNT randomly in the whole sample matrix as frequently done. This local sensor could be deposited on the surface of the composite specimen by resin casting [42,43], spraying [18], or printing [44-47]. This smart microply can be inserted during processing, in the part's core. The sensor's sensitivity can be furthermore adjusted with the nanofiller content in the polymer according to the percolation law [19]. Using a CNT-filled epoxy nanocomposite, just above its percolation threshold around $0.5 \mathrm{wt} \%$, allows to reach gauge factors (GF) as high as 78 [45], while at $0.7 \mathrm{wt} \%$ the GF decreases to 3.2 [43]. Such sensors typically have a thickness ranging from $1 \mu \mathrm{m}[18]$ to $100 \mu \mathrm{m}$ [43].

Michelis et al. [48] also proposed inkjet-printed CNT based strain sensors made directly on a polymer substrate with a GF of 0.98. A similar process has been used by Kaiyan et al. [49] with the addition of epoxy in the sensor, reaching a GF of 50. Dai et al. [50] chose a cost-effective process based on a non-woven aramid carrier fabric soaked in a CNTfilled solution to fabricate a sensor, achieving a linear response and an elastic gauge factor of 1.9 .

Nevertheless, the sensors were located on the surface of samples, which avoided the in situ core measurements potentially affecting them by moisture and temperature. Another strategy developed by Feller et al. $[19,29]$ is to embed in the composite during its processing 
a premade sensing patch obtained by spraying layer-by-layer (sLbL) CNT-epoxy solutions on a glass fiber textile.

In this case, the dimensions of the transducer as well as the electrode design can be fixed "on-demand", depending on the desired configuration in the host. These so-called quantum resistive sensors (QRS), can be made of the same resin as the composite and be cured to the same level of crosslinking degree to guaranty a complete homogeneity of thermal and mechanical properties. Conveniently, the resulting sensitivity to strain (GF) can be adjusted by changing the filler content or the number of sprayed layers [19]. Finally, QRS derive their great sensitivity to their environment, and in particular to nanodeformations from the percolated nature of their sensing architecture favoring tunneling conduction to the detriment of classical ohm conduction, which tend to produce an exponential variation of the resistive response upon an increase of the interparticular distance " $d$ " as shown in Equation (1).

$$
R_{\text {tunnel }}=\frac{V}{A J}=\frac{h^{2} d}{A e^{2} \sqrt{2 m \lambda}} \exp \left(\frac{4 \pi d}{h} \sqrt{2 m \lambda}\right)
$$

where $J$ is the tunneling current density; $V$ is the electrical potential difference; $A$ is the cross-sectional area of tunnel; $e$ is the quantum of electricity; $m$ is the mass of electron; $h$ is Plank's constant; $d$ is the distance between conductive particles; 1 is the height of energy barrier (for epoxy, 0.5-2.5 eV).

In this work, the use of CNT-epoxy Quantum Resistive Sensors (QRS), placed at different locations into the core of carbon-fiber reinforced polymer (CFRP) samples is reported, as illustrated in Figure 1. QRS are integrated during the laminate manufacturing process and are not limited by the shape or angle of the composite part. The evolution of the electrical behavior of several QRS during a mechanical deformation as a function of their location inside the structure is investigated (within a ply of the laminate, and between the plies, i. e. through thickness). The QRS network thus formed could be used from the elastic deformation to the final breakage of the composite and provide a location of the stress experienced in the structure.

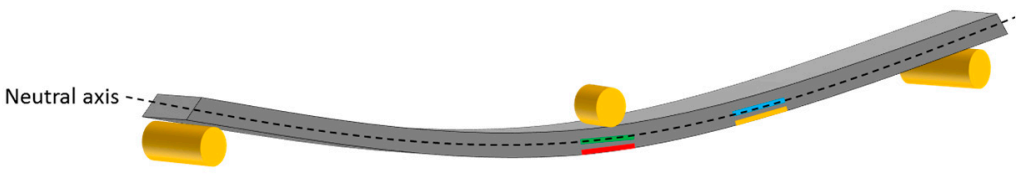

Figure 1. Representation of three points bending experiments with Quantum Resistive Sensor (QRS) placed in the tensile zone.

\section{Experimental Details}

\subsection{Materials}

The Carbon fiber reinforced polymer (CFRP) prepreg was purchased from Hexcel. The carbon fiber is a taffetas fabric $\left(0 / 90^{\circ}, 300 \mathrm{~g} / \mathrm{m}^{2}\right)$ with $34 \%$ in weight in a M79 epoxy resin. Multiwall carbon nanotubes $\left(\mathrm{NC}-7000^{\mathrm{TM}}\right.$ ) were kindly provided by Nanocy ${ }^{\circledR}$ (Sambreville, Belgium). This grade corresponds to MWCNT with an average diameter of $10 \mathrm{~nm}$ and a mean length comprised between 100 and $1000 \mathrm{~nm}$. Epolam 2020 epoxy resin \& amine hardener were purchased from Axson Technologies (Saint-Ouen, France), glass fiber was purchased from Composites Distribution ${ }^{\circledR}$ (Orvault, France) and chloroform (99\%) was purchased from Sigma-Aldrich (Saint-Quentin, France).

\subsection{Manufacture of Samples}

Calculated amounts of CNT and epoxy resin were homogenized in chloroform by ultra-sonication with a Branson 3510 sonicator for $90 \mathrm{~min}$ at $25^{\circ} \mathrm{C}$, and further degassed for $5 \mathrm{~min}$. After dispersion of the CNTs in the epoxy resin, an amine hardener was added and the mixture was sonicated for $30 \mathrm{~min}$. The obtained mixing contains $3 \%$ by weight of CNT in the epoxy. $7 \mathrm{~mm} \times 3 \mathrm{~mm}$ thin-film sensors were obtained by the technique of spraying via layer-by-layer (sLbL) deposition and can be seen in Figure $2 b$. The electrical connections 
were made with silver-based ink. The solutions were sprayed with our homemade device onto the supporting glass fiber/epoxy film allowing a precise control of nozzle scanning speed $\left(10 \mathrm{~cm} \mathrm{~s}^{-1}\right)$, solution flow rate $\left(50 \mathrm{~mm} \cdot \mathrm{sec}^{-1}\right)$, stream pressure $(0.20 \mathrm{MPa})$, and target to nozzle distance $(8 \mathrm{~cm})$. The QRS was then insulated with a layer of glass fiber/epoxy substrate. The QRS are embedded into the CFRP during the stacking sequence (16 plies). 4 locations are selected and their coordinates are related to the position of loading pin (X; $Z)$, as illustrated in Figure 2a,c. A pair of QRSs aligned on the centreline of the loading pin (X0), under the first ply (X0; Z0) and in the mid-thickness of the CFRP (X0; Z-1/2), respectively. A second pair is located at the same depths, but offset by a quarter of the length of the sample, $(\mathrm{X} 1 / 4 ; \mathrm{Z} 0)$ and $(\mathrm{X} 1 / 4 ; \mathrm{Z}-1 / 2)$ respectively. Curing is carried out by a $6 \mathrm{~h}$ heat treatment at $80^{\circ} \mathrm{C}$ ensuring complete crosslinking and the resulting CFRP sample dimensions are $400 \times 50 \times 3.2 \mathrm{~mm}^{3}$.

(a)

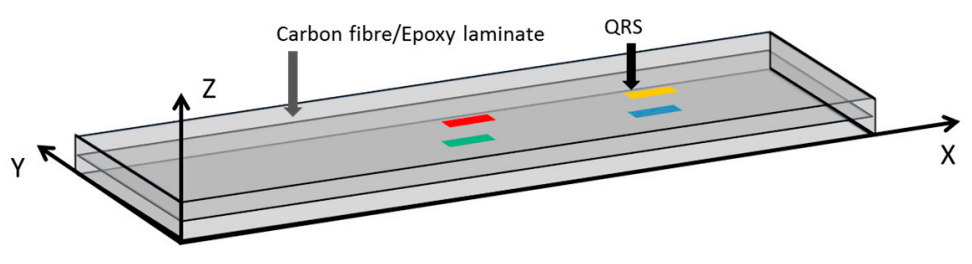

(b)

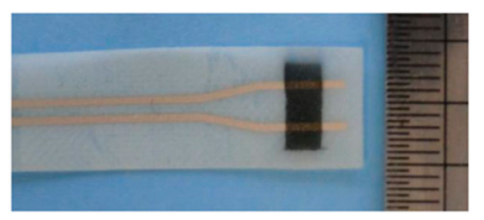

(c)

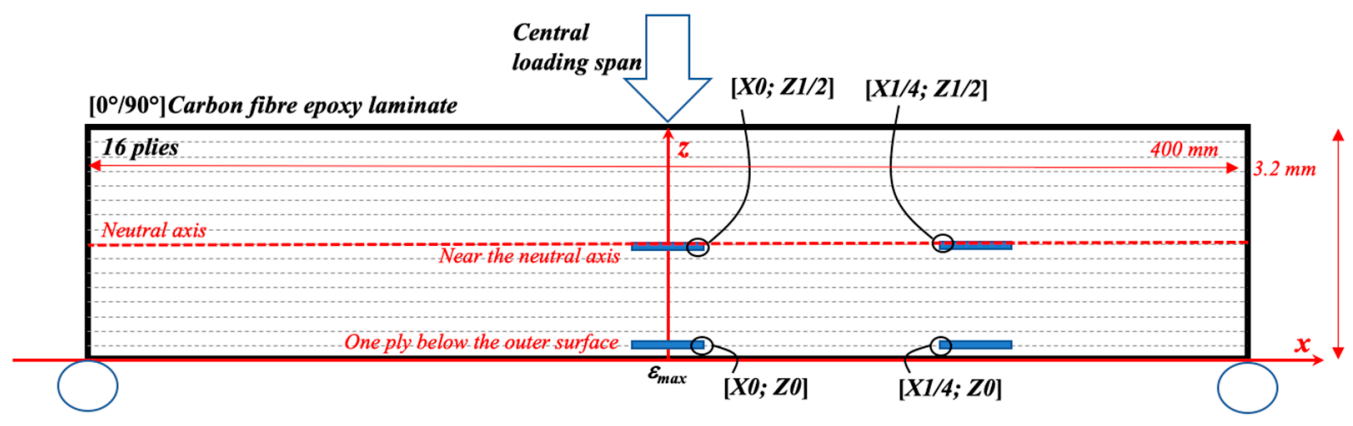

Figure 2. (a) Diagram of the CFRP specimen with embedded QRS below the surface and in the region of the neutral axis along with their name and position in the laminate. (b) Photography of a QRS, including the substrate (whitish area), the conductive silver-based tracks and the active CNT-filled QRS (dark area) (c) Representation of the CFRP specimen and the detailed location of the QRS during three-point bending experiments (QRS placed in the tension zone).

\subsection{Characterization Techniques}

An Instron 5566A servo-hydraulic was used to perform static three-point bending experiments, according to the standard NF EN ISO 14125. An Instron Electropuls E10000 was used to perform dynamic three-point bending experiments with the same apparatus as for the static tests.

The fracture profile was obtained by Scanning Electron Microscopy (SEM) using a Jeol series model (JSM-6031F) (JEOL Europe SAS, Croissy Sur Seine, France).

In situ electrical measurements were carried out by an HBM quantum 840 device with a direct current of $1 \mathrm{~V}$ applied to the QRS.

\section{Results and Discussion}

\subsection{Mechanical Properties of the Sample with and without Embedded QRS}

In order to study the effect of QRS on the mechanical performance of the CFRP sample, three-point static bending experiments were performed with and without QRS embedded in the sample core, as presented in Figure 3a. Both cases show similar behavior with 
first a linear increase in stress with strain up to $0.5 \%$ in the elastic range, followed by a slight reduction in the stress increase due to the initiation cracks at the $90^{\circ}$ fibers interfaces and their propagation in the matrix until final failure around $1.4 \%$ [51]. The resulting mechanical properties, summarized in Table 1, are consistent with the literature data for the pristine $0 / 90^{\circ}$ carbon fiber epoxy composite [52,53]. In addition, the introduction of QRS modifies the modulus, failure stress and failure strain by 1.2, 6.0 and 5.6\% respectively, which are still within the measurement uncertainty.

(a)

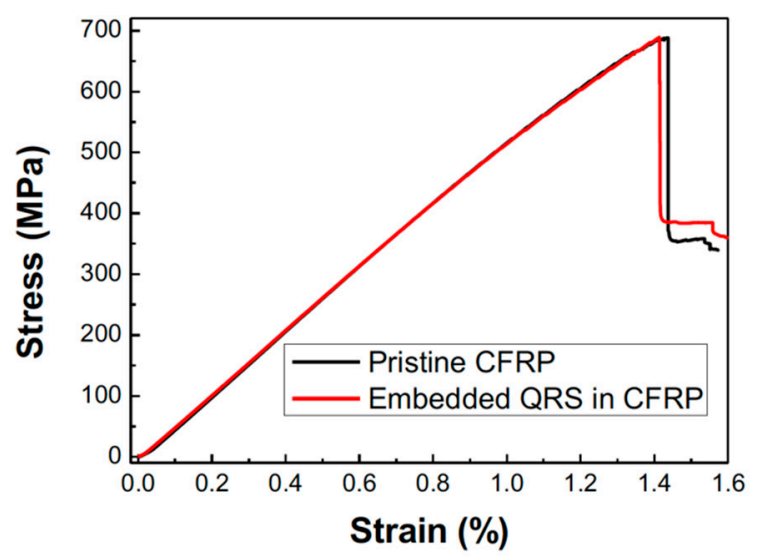

(b)
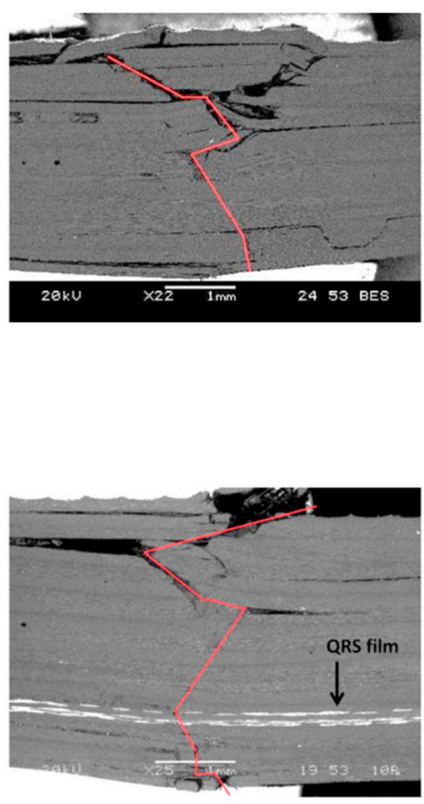

(c)

Figure 3. (a) Static three-point bending mechanical behavior of a CFRP composite with and without embedded QRS displaying equivalent behavior. Fracture profile under the central span (b) with and (c) without embedded QRS. The red line represents the fracture path.

Table 1. Mechanical properties of a CFRP composite $\left(0 / 90^{\circ}\right)$ with and without embedded QRS in static three-point bending, according to standard NF EN ISO 14125.

\begin{tabular}{cccc}
\hline Type of Sample & $\begin{array}{c}\text { Young Modulus } \\
\mathbf{( G P a )}\end{array}$ & $\begin{array}{c}\text { Failure Stress } \\
\mathbf{( M P a )}\end{array}$ & $\begin{array}{c}\text { Failure Strain } \\
\mathbf{( \% )}\end{array}$ \\
\hline Pristine CFRP & $52.1 \pm 1.8$ & $669 \pm 27$ & $1.42 \pm 0.06$ \\
CFRP with embedded QRS & $51.5 \pm 2.1$ & $629 \pm 61$ & $1.34 \pm 0.11$ \\
\hline
\end{tabular}

The regions where the rupture occurred were observed by the SEM as shown in Figure $3 b, c$. It was detected that the onset of failure occurred on both sides of the sample and propagated through the thickness while the delaminations are parallel to the plane of the fabric. This behavior is in line with that expected for the $0 / 90^{\circ}$ composite under bending solicitation [53]. Samples with in-core QRS do not show additional delamination or failure compared to the blank samples, confirming that the mechanical properties are not affected by the introduction of QRS. 


\subsection{Electrical Response of QRS According to Their Location in the Specimen}

QRS were incorporated at four different locations in the CFRP samples, as described earlier. Two were one ply below the surface, one below the central span and one offset $100 \mathrm{~mm}$ to the side of the sample. Two others QRS were placed at the same X-positions, but in depth, on the neutral axis of the sample. Because of these different locations, QRS are subject to different level of strain, as shown in the following equation:

$$
\varepsilon=\frac{24 f v x}{L^{3}}
$$

where $\varepsilon$ is the strain, $f$ is the deflection, $v$ is the distance from the neutral axis, $x$ is the position along the sample, and $L$ is the length between the two external spans.

As already shown $[19,32,37,54]$, QRS are displaying a change in electrical resistance with strain, which is characterized by the Gauge Factor (GF), defined as follows:

$$
G F=\frac{A r}{\varepsilon}=\frac{\Delta R / R_{0}}{\varepsilon}
$$

where $\Delta R$ is the change of electrical resistance compared to $\varepsilon=0, R_{0}$ is the initial resistance at $\varepsilon=0$, and $A r$, the relative amplitude of the electrical resistance, i.e., the ratio $\Delta R / R_{0}$.

It has been previously estimated that for such embedded sensors with an initial resistance of about $20 \mathrm{k} \Omega$, the GF is about 3 [19]. Therefore, in order to represent the effect of the sensor position, the electrical response has been normalized to the maximum value obtained for QRS (X0; Z0), which is assumed to be subject to the maximum strain and thus exhibit the highest response. Figure 3a represents the normalized amplitude of the electrical resistance of the four QRS, with the strain measured below the central span in a static three-points bending experiment, which is supposed to be the maximum strain value.

QRS placed a ply below the surface, e.g., QRS (X0, Z1/4), depicts a behavior similar to QRS $(X 0, Z 0)$. An initial growth in resistance is visible up to $0.1 \%$, followed by a steadier increase in resistance. The final value reached by the QRS $(\mathrm{X} 0 ; \mathrm{Z} 0)$ is almost double that of the QRS $(X 1 / 4 ; Z 0)$ one. This result is consistent with Equation (2) and Figure 4c,d, where the strain under the center span at the $X 1 / 2$ position is about twice that of the position LX1/4. In addition, the stress undergone at the center QRS is higher, which may result in a noisier signal compared to others QRS. In the case of the QRS placed near the neutral axis, the resistance variation is almost equal to 0 . This is consistent and corresponds to the fact that there is no deformation on the neutral axis. Focusing on the curves in Figure $4 \mathrm{~b}$. It can be seen that the QRS (X0; Z-1/2) is nevertheless subjected to an initial increase in resistance up to $0.3 \%$ followed by a slight decrease, while the QRS $(X 1 / 4 ; Z-1 / 2)$ displays a decrease in resistance throughout the bending test. This indicates their proximity to the neutral axis and the resulting nearly total absence of resulting strain. Thanks to the variation of the behavior as a function of the position, it demonstrates the ability of QRS to provide in situ measurements of the strain encountered, both along the sample and through the thickness. Although CFRP is an electrically conductive material, the absence of short circuits and the individual response of each QRS demonstrate the ability of the supporting film to isolate the QRS from the carbon fibers-reinforced composite.

In order to demonstrate the ability of the QRS to detect dynamic deformations, cycling tests were also performed in addition to the static test. Figure 5a shows the normalized change in QRS resistance with strain over 30 sinusoidal cycles. As expected and observed during the static test, although having the same gauge factor, one can see in Figure $5 b$ that the amplitude of their electrical signal relates to their position in the composite. Indeed, the QRS positioned on the side (X1/4) displays a smaller change in resistance with the strain than the one placed under the center span $(\mathrm{X} 0)$ and, near the neutral axis, almost no change in resistance is visible. The absence of hysteresis and the ability of QRS to follow the sinusoidal cycles confirm their possible use for dynamic in situ measurements. To further investigate the sensing capability of QRS in tension and compression, Figure $5 c$,d presents the dynamic three-points bending test of a CFRP specimen equipped with QRS located 
one ply below the surface, i.e., $\mathrm{QRS}(\mathrm{X} 0 ; \mathrm{Z} 0), \mathrm{QRS}(\mathrm{X} 0 ; \mathrm{Z1} / 4)$ in the tensile side and QRS (X0; Z-1), QRS (X1/4; Z-1) in the compression side. The strain ranged from 0 to $0.1 \%$. QRS displayed two symmetrically opposite electrical behaviors in tension and compression with a maximum normalized Ar of 0.089 and -0.085 for traction and compression. respectively. As observed earlier in static tension mode, when the sample is moved from the position $\mathrm{X} 0$ to the $\mathrm{X} 1 / 4$ position, the electrical response is two times less, which is consistent with Equation (2) and Figure 4c,d. As a result, QRS showed three distinct electrical behaviors, whether in traction, compression or on the neutral axis. They can therefore be used to measure the deformations experienced by the laminate composite, both on the surface and in the core of the part. The use of multiple QRS could be envisaged to map selected areas of the composite part in three dimensions.

(a)

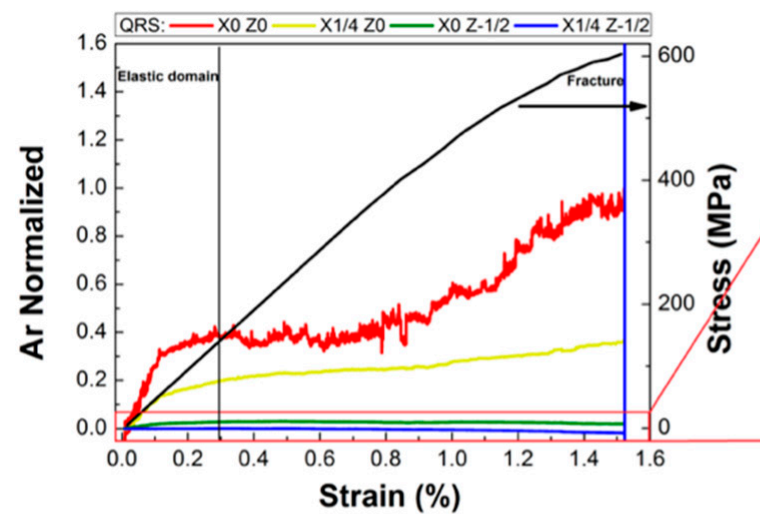

(c)

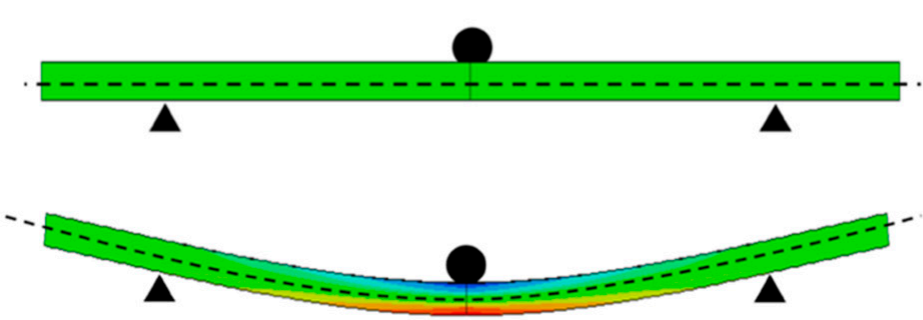

(b)
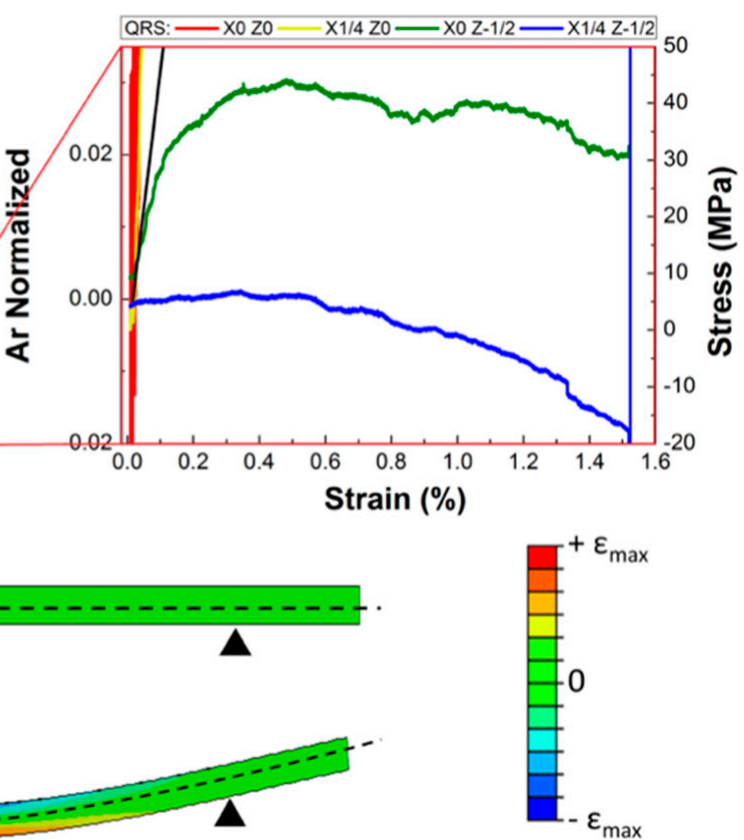

Figure 4. Electrical behavior of four QRS located at four different spots in the CFRP sample, below the central span (identification $\mathrm{X} 0$ ), or in the middle along the side of the sample (X1/4), and one ply below the surface (Z0) or close to the neutral axis (Z-1/2). (a) Normalized Ar of the four QRS as a function of the maximum strain below the central span during static three-points bending test. (b) Magnification of curves for $(X 0 ; Z-1 / 2)$ and $(X 1 / 4 ; Z-1 / 2)$. Modelling of the strain field during the three-points bending experiment at (c) initial state and (d) during bending.

To verify the reversibility of the QRS response, specimens were submitted to 300 consecutive cycles in the elastic domain and above the elastic limit. Figure 6a represents the strain imposed over time. Increasing successive stages are visible, with one below the elastic limit (average strain $\varepsilon_{1}=0.15 \%$ ), one close to the elastic limit $\left(\varepsilon_{2}=0.30 \%\right)$, one above the elastic limit $\left(\varepsilon_{3}=0.80 \%\right)$ and on close to the final breakage $\left(\varepsilon_{4}=1.13 \%\right)$. These steps are interspersed with periods of solicitation referenced (labelled $\varepsilon_{1}, \varepsilon_{1}-2, \varepsilon_{1}-3, \varepsilon_{1}-4$ ) to a strain of $\varepsilon_{1}=0.15 \%$. The range of deformation variation around the mean values during the step as was chosen at $0.06 \%$ to avoid any additional defects formation during the complete cycling test. 
(a)

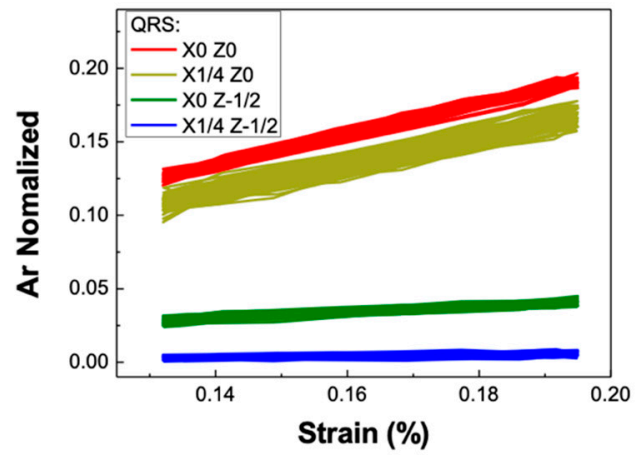

(c)

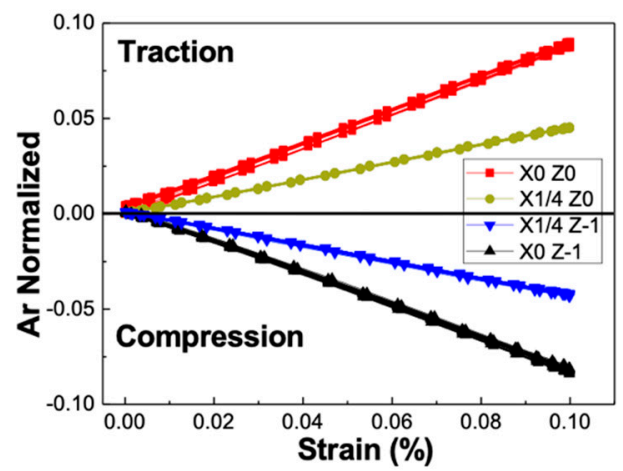

(b)

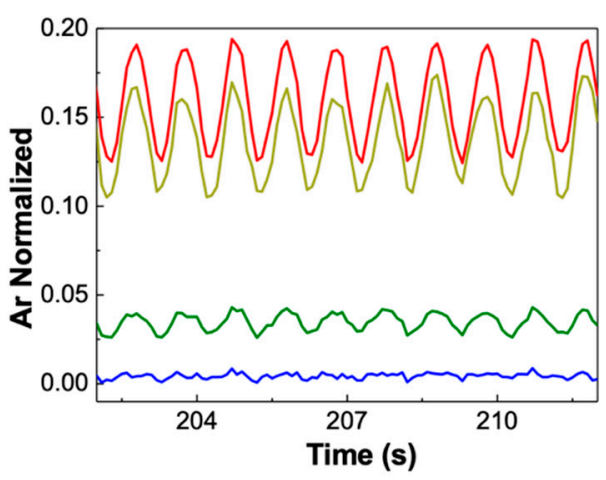

(d)

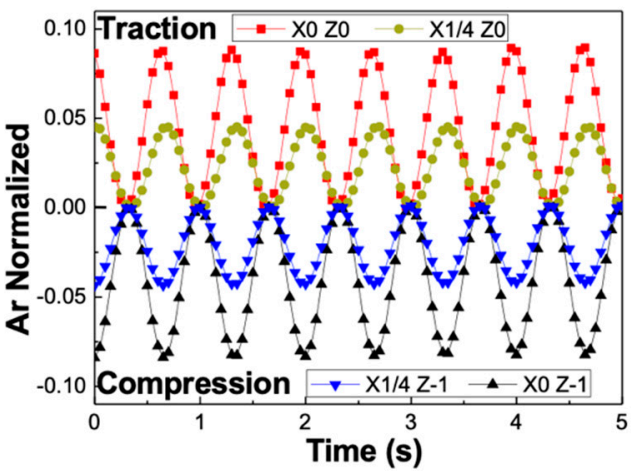

Figure 5. Electrical behavior of four QRS located at four different locations in the CFRP specimen, below the center span (identification $X 0)$, or in the middle along the side of the specimen (X1/4), and one ply below the surface (Z0) or near the neutral axis (Z-1.2). (a) Normalized electrical resistance (Ar) of the four QRS with maximum strain during dynamic elastic three-points bending test. (b) Representation of their electrical response with time according to the deflection of the beam. (c) Electrical behavior of the QRS located on the compression side, $(X 0 ; Z-1)$ and $(X 1 / 4 ; Z-1)$, or the tension side, (X0; Z0) and $(X 1 / 4 ; Z 0)$, during the dynamic three-points bending test. (d) Representation of their electrical response associated with time for a given deflection.

Figure $6 \mathrm{~b}$ shows the average value of the QRS response during the increasing stages of the cycle and the scale bars correspond to the total amplitude of the signal. QRS have a behavior equivalent to that of static deformation where the increase in Ar depends on the location of the QRS. The average increase in Ar and the increase in the amplitude of Ar moving on the one hand from the neutral axis to the tensile side, and on the other hand from the side to the underside of the central span. With the exception of QRS $(X 1 / 4 ; Z 0)$ in the last step $\left(\varepsilon_{4}\right)$, the amplitude of Ar is also constant for all steps, as shown in Table 2 . This indicates that once a level of strain above the elastic limit is obtained, small mechanical solicitations do not deteriorate the specimen and the resulting QRS response. In addition, the modified behavior displayed by the QRS $(\mathrm{X} 1 / 4 ; \mathrm{Z} 0)$ in the last step can be associated with the increase in nearby defects and in the QRS. The QRS can therefore attest to the local degradation of the material. 


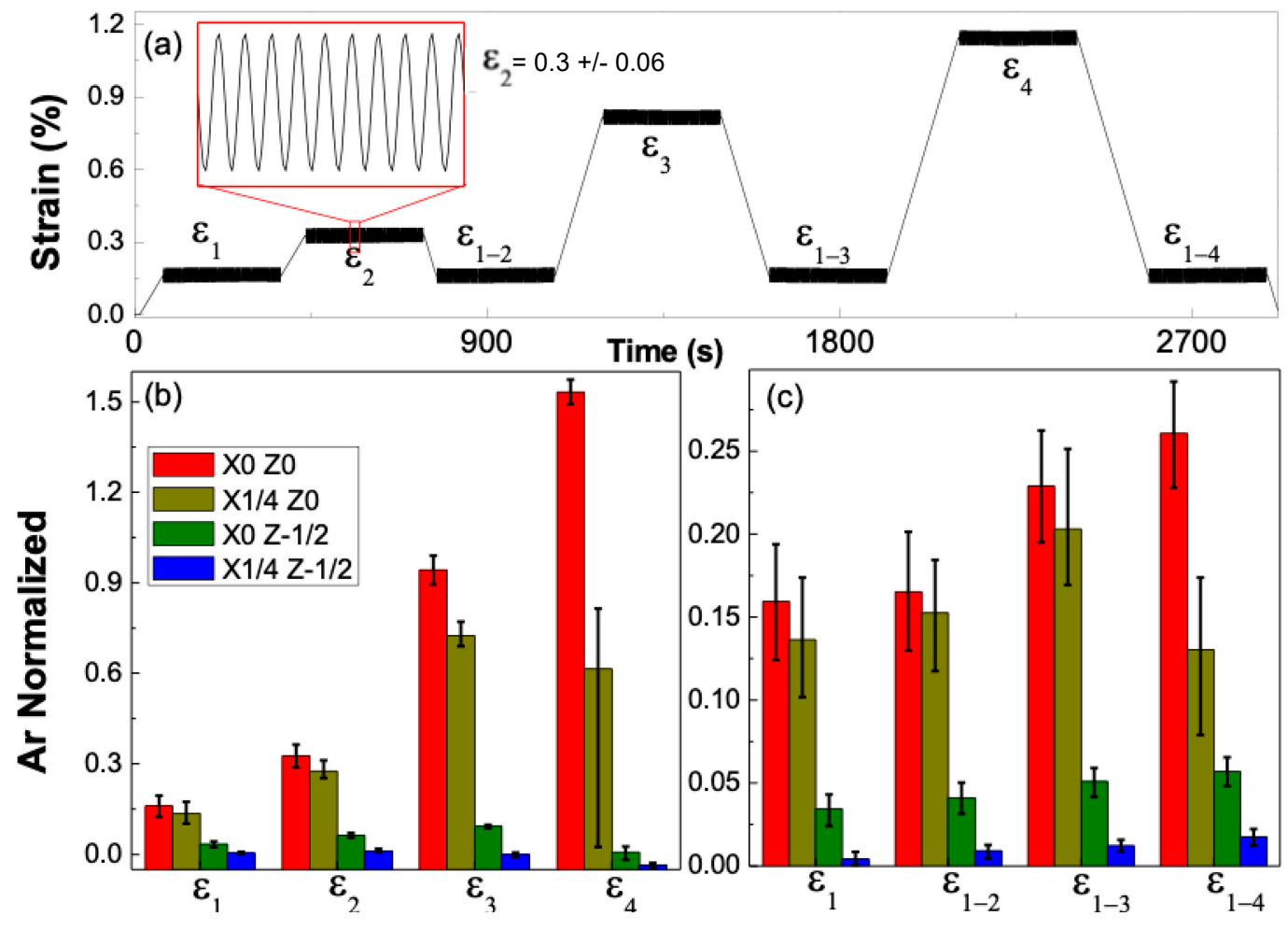

Figure 6. Dynamic deformation of a CFRP specimen with four QRS located below the center span (identification X0), or in the middle along the side of the specimen (X1/4), and one ply below the surface $(\mathrm{Z} 0)$ or near the neutral axis $(\mathrm{Z}-1 / 2)$. (a) Four stages of increasing strain applied to the specimen and the reference strain periods/plateaux. The inset represents a magnification of the sinusoidal load applied to the sample during the test. In each sections, the sample is subjected to a dynamic sinusoidal bending load of a small amplitude $(+/-0.06)$ around a fixed value $\left(\varepsilon_{1}, \varepsilon_{2}\right.$ etc.). (b) Average value of the relative electrical amplitude of QRS in the four increasing steps. The scale bars represent the amplitude of the dynamic response. (c) Average value of the relative amplitudes of the QRS during reference periods of low strain. The scale bars represent the amplitude of the dynamic response to a small variation of $+/-0.06 \%$ around a fixed $\varepsilon_{\mathrm{i}}$ value.

Table 2. QRS response amplitude during the cycling steps.

\begin{tabular}{ccccc}
\hline Step & $\mathbf{( X 0 ; ~ Z 0 )}$ & $\mathbf{( X 1 / 4 ; ~ Z 0 )}$ & $\mathbf{( X 0 ; ~ Z - 1 / 2 ) ~}$ & $\mathbf{( X 1 / 4 ; ~ Z - 1 / 2 ) ~}$ \\
\hline$\varepsilon_{1}$ & 0.070 & 0.072 & 0.019 & 0.008 \\
$\varepsilon_{2}$ & 0.075 & 0.072 & 0.015 & 0.011 \\
$\varepsilon_{1-2}$ & 0.072 & 0.067 & 0.019 & 0.008 \\
$\varepsilon_{3}$ & 0.096 & 0.082 & 0.012 & 0.014 \\
$\varepsilon_{1-3}$ & 0.067 & 0.082 & 0.017 & 0.007 \\
$\varepsilon_{4}$ & 0.080 & 0.79 & 0.044 & 0.015 \\
$\varepsilon_{1-4}$ & 0.064 & 0.095 & 0.017 & 0.010 \\
\hline
\end{tabular}

Figure 6c shows the QRS response during the steps of the reference cycle and the scale bars correspond to the total amplitude of the signal. For all QRSs, the first two reference steps $\left(\varepsilon_{1}, \varepsilon_{1-2}\right)$ give equal responses. For consecutive reference steps $\left(\varepsilon_{1-3}, \varepsilon_{1-4}\right)$, a residual Ar is visible for all QRS and is greater on the tensile side and under the center span. Chowdhury et al. [19] reported a fairly similar electrical behavior in the case of increasing static tensile cycles. Residual strain is due to the formation and propagation of cracks in the material. Once the elastic limit of the sample is exceeded, the defects and cracks created are mainly located in the region below the centre span. Thus, the residual Ar is higher for the QRS (X0; Z0) because it is located in the most damaged region. Therefore, the Ar drift is an indicator of the amount of core damage and it is conceivable that the use of a discrete number of QRS can be used to locate the main affected area in the specimen. 


\section{Conclusions}

The integration of an array of four Quantum Resistive Sensors was carried out for the first time to map the deformation gradient inside epoxy-carbon fiber laminate composite samples, i.e., in plane and through thickness. It was also demonstrated that the presence of QRS did not affect the mechanical behavior and properties of the CFRP samples. The gauge factor of QRS was selected around 3, being a compromise between sensitivity and noise ratio. Although higher gauge factor can be found in the literature, this sensitivity was found sufficient to monitor very small deformation in the core of the composite $(0.06 \%)$. The integration inside a carbon fiber reinforced composite was made possible thanks to insulation of the sensors which opens applications in the high-performance composites area previously reserved for optical fibers. QRS were tested in both static and dynamic experiments. The robustness of sensors to follow sinusoidal solicitation at different amplitude was demonstrated.

In addition, the electrical response of QRS, conditioned by their location in the samples, allowed to determine the local deformation. A positive response was observed on the side of the composite sample submitted to tension, whereas the sensors located near the neutral axis exhibited almost no response. For the two sensors located in the same ply, a lower response was found for the QRS located away from the loading span being consistent with the beam theory. The precise spatial location of sensors could thus be used to map the deformation gradient and eventually feed a simulation software.

A part from deformation measurements, the sensors proved to be able to follow damage up to failure in static mode. In dynamic mode, a transition in behavior was observed through the variation of sensitivity of sensors over a limit of $0.8 \%$, assumed to be the elastic limit, suggesting that sensors could be used to track damage accumulation.

Further investigations will concern the implementation of a larger number of QRS in $3 \mathrm{D}$ in a laminate composite part in order to map the strain field in selected area. Other modes of solicitation such as compression, shear or impact, as well as long-term experimentation (fatigue) should be studied in order to broaden the fields of application and specially to get closer to the real environmental conditions of use

This could be of great interest to monitor the health of composite in the energy and transport fields, such as turbine blades or boat foils.

Author Contributions: Conceptualization, M.C., J.-F.F.; methodology, A.L., M.C., J.-F.F.; validation, A.L., M.C., J.-F.F., O.F.; formal analysis, A.L., M.C., J.-F.F.; investigation, A.L., M.C., J.-F.F.; resources M.C., J.-F.F.; writing—original draft preparation, A.L.; writing-review and editing, A.L., M.C., J.-F.F.; visualization, A.L., M.C., J.-F.F.; supervision, M.C.; project administration, O.F., J.-C.D.L., J.-F.F.; funding acquisition, J.-C.D.L., J.-F.F. All authors have read and agreed to the published version of the manuscript.

Funding: EVEREST Project (funded by IRT Jules Verne and G.E.).

Acknowledgments: The authors would like to specially thank Hervé Bellegou for developing the electrical acquisition system.

Conflicts of Interest: The authors declare no conflict of interest.

\section{References}

1. Burck, J.; Marten, F.; Bals, C.; Dertinger, A.; Uhlich, T. Climate Change Performance Index Results 2017. Available online: https:/ / germanwatch.org/en/13042 (accessed on 19 February 2021).

2. UNFCCC. Adoption of the Paris Agreement: Proposal by the President to the United Nations Framework Convention on Climate Change. 2015. Available online: https:/ / unfccc.int/documents/9064 (accessed on 19 February 2021).

3. Islam, M.; Mekhilef, S.; Saidur, R. Progress and recent trends of wind energy technology. Renew. Sustain. Energy Rev. 2013, 21, 456-468. [CrossRef]

4. Kumar, Y.; Ringenberg, J.; Depuru, S.S.; Devabhaktuni, V.K.; Lee, J.W.; Nikolaidis, E.; Andersen, B.; A Afjeh, A. Wind energy: Trends and enabling technologies. Renew. Sustain. Energy Rev. 2016, 53, 209-224. [CrossRef]

5. Jones, R.M. Mechanics of Composite Materials; Taylor \& Francis: New York, NY, USA, 1998. 
6. Syndicat des Energies Renouvelables, Etat des Coûts de Production de L'éolien Terrestre en France Analyse Economique de la Commission Eolienne du SER. 2014. Available online: https://www.syndicat-energies-renouvelables.fr/les-energiesrenouvelables/eolien/eolien-terrestre/ (accessed on 19 February 2021).

7. The Tide Turns on Offshore Maintenance Costs. Windpower Offshore. Available online: https:/ www.windpowermonthly.com/ article/1314299/tide-turns-offshore-maintenance-costs (accessed on 19 February 2021).

8. Floating Offshore Wind Farms; Springer International Publishing: Cham, Switzerland, 2016.

9. Schubel, P.; Crossley, R.; Boateng, E.; Hutchinson, J. Review of structural health and cure monitoring techniques for large wind turbine blades. Renew. Energy 2013, 51, 113-123. [CrossRef]

10. Structural Health Monitoring Person of the Year Award. Struct. Heal. Monit. 2008, 7, 89-90. [CrossRef]

11. Huston, D. Structural Sensing, Health Monitoring and Performance Evaluation; Series in Sensors; CRC Press: Boca Raton, FL, USA, 2010.

12. Farrar, C.R.; Worden, K. An introduction to structural health monitoring. Philos. Trans. R. Soc. A Math. Phys. Eng. Sci. 2006, 365, 303-315. [CrossRef]

13. Raman, V.; Drissi-Habti, M.; Guillaumat, L.; Khadhour, A. Numerical simulation analysis as a tool to identify areas of weakness in a turbine wind-blade and solutions for their reinforcement. Compos. Part B Eng. 2016, 103, 23-39. [CrossRef]

14. Resor, B.R. Definition of a 5 MW/61.5 m Wind Turbine Blade Reference Model. 2013. Available online: https:/ / prod.sandia.gov/ techlib-noauth/access-control.cgi/2013/132569.pdf (accessed on 19 February 2021).

15. Holmes, C.; Godfrey, M.; Bull, D.J.; Dulieu-Barton, J. Real-time through-thickness and in-plane strain measurement in carbon fibre reinforced polymer composites using planar optical Bragg gratings. Opt. Lasers Eng. 2020, 133, 106111. [CrossRef]

16. Iijima, S. Helical microtubules of graphitic carbon. Nat. Cell Biol. 1991, 354, 56-58. [CrossRef]

17. Radushkevich, L.V.; Lukyanovich, V.M. About the structure of carbon formed by thermal decomposition of carbon monoxide on iron substrate. J. Phys. Chem. 1952, 26, 88-95.

18. Robert, C.; Feller, J.F.; Castro, M. Sensing Skin for Strain Monitoring Made of PC-CNT Conductive Polymer Nanocomposite Sprayed Layer by Layer. ACS Appl. Mater. Interfaces 2012, 4, 3508-3516. [CrossRef]

19. Nag-Chowdhury, S.; Bellegou, H.; Pillin, I.; Castro, M.; Longrais, P.; Feller, J. Non-intrusive health monitoring of infused composites with embedded carbon quantum piezo-resistive sensors. Compos. Sci. Technol. 2016, 123, 286-294. [CrossRef]

20. Gao, L.; Thostenson, E.T.; Zhang, Z.; Chou, T.-W. Coupled carbon nanotube network and acoustic emission monitoring for sensing of damage development in composites. Carbon 2009, 47, 1381-1388. [CrossRef]

21. Gao, L.; Thostenson, E.T.; Zhang, Z.; Chou, T.-W. Sensing of Damage Mechanisms in Fiber-Reinforced Composites under Cyclic Loading using Carbon Nanotubes. Adv. Funct. Mater. 2009, 19, 123-130. [CrossRef]

22. Wichmann, M.H.G.; Buschhorn, S.T.; Gehrmann, J.; Schulte, K. Piezoresistive response of epoxy composites with carbon nanoparticles under tensile load. Phys. Rev. B 2009, 80, 245437. [CrossRef]

23. Böger, L.; Wichmann, M.H.; Meyer, L.O.; Schulte, K. Load and health monitoring in glass fibre reinforced composites with an electrically conductive nanocomposite epoxy matrix. Compos. Sci. Technol. 2008, 68, 1886-1894. [CrossRef]

24. Sebastian, J.; Schehl, N.; Bouchard, M.; Boehle, M.; Li, L.; Lagounov, A.; Lafdi, K. Health monitoring of structural composites with embedded carbon nanotube coated glass fiber sensors. Carbon 2014, 66, 191-200. [CrossRef]

25. Gojny, F.H.; Wichmann, M.H.; Fiedler, B.; Bauhofer, W.; Schulte, K. Influence of nano-modification on the mechanical and electrical properties of conventional fibre-reinforced composites. Compos. Part A Appl. Sci. Manuf. 2005, 36, 1525-1535. [CrossRef]

26. Tripathi, K.M.; Vincent, F.; Castro, M.; Feller, J.F. Flax fibers-epoxy with embedded nanocomposite sensors to design lightweight smart bio-composites. Nanocomposites 2016, 2, 125-134. [CrossRef]

27. Chowdhury, S.N.; Tung, T.T.; Ta, Q.T.H.; Kumar, G.; Castro, M.; Feller, J.-F.; Sonkar, S.K.; Tripathi, K.M. Upgrading of Diesel Engine Exhaust Waste into Onion-like Carbon Nanoparticles for Integrated Degradation Sensing in Nano-biocomposites. New J. Chem. 2021. [CrossRef]

28. Treacy, M.M.J.; Ebbesen, T.W.; Gibson, J.M. Exceptionally high Young's modulus observed for individual carbon nanotubes. Nat. Cell Biol. 1996, 381, 678-680. [CrossRef]

29. Pillin, I.; Castro, M.; Chowdhury, S.N.; Feller, J.-F. Robustness of carbon nanotube-based sensor to probe composites' interfacial damage in situ. J. Compos. Mater. 2015, 50, 109-113. [CrossRef]

30. Robert, C.; Pillin, I.; Castro, M.; Feller, J.-F. Multifunctional Carbon Nanotubes Enhanced Structural Composites with Improved Toughness and Damage Monitoring. J. Compos. Sci. 2019, 3, 109. [CrossRef]

31. Fidelus, J.; Wiesel, E.; Gojny, F.; Schulte, K.; Wagner, H. Thermo-mechanical properties of randomly oriented carbon/epoxy nanocomposites. Compos. Part A Appl. Sci. Manuf. 2005, 36, 1555-1561. [CrossRef]

32. Gojny, F.H.; Wichmann, M.H.; Fiedler, B.; Kinloch, I.A.; Bauhofer, W.; Windle, A.H.; Schulte, K. Evaluation and identification of electrical and thermal conduction mechanisms in carbon nanotube/epoxy composites. Polymer 2006, 47, 2036-2045. [CrossRef]

33. Feller, J.-F. 6.10 Electrically Conductive Nanocomposites. In Comprehensive Composite Materials II; Elsevier BV: Amsterdam, The Netherlands, 2018; pp. 248-314.

34. Ebbesen, T.W.; Lezec, H.J.; Hiura, H.; Bennett, J.W.; Ghaemi, H.F.; Thio, T. Electrical conductivity of individual carbon nanotubes. Nat. Cell Biol. 1996, 382, 54-56. [CrossRef]

35. Feller, J.-F.; Kumar, B.; Castro, M. Conductive biopolymer nanocomposites for sensors. Nanocompos. Biodegrad. Polym. 2011, 368-399. [CrossRef] 
36. Levin, Z.S.; Robert, C.; Feller, J.F.; Castro, M.; Grunlan, J.C. Flexible latex-polyaniline segregated network composite coating capable of measuring large strain on epoxy. Smart Mater. Struct. 2012, 22, 1-9. [CrossRef]

37. Thostenson, E.T.; Chou, T.-W. Real-timein situsensing of damage evolution in advanced fiber composites using carbon nanotube networks. Nanotechnology 2008, 19, 215713. [CrossRef] [PubMed]

38. Tzounis, L.; Zappalorto, M.; Panozzo, F.; Tsirka, K.; Maragoni, L.; Paipetis, A.S.; Quaresimin, M. Highly conductive ultra-sensitive SWCNT-coated glass fiber reinforcements for laminate composites structural health monitoring. Compos. Part B Eng. 2019, 169, 37-44. [CrossRef]

39. Wang, Y.; Wang, Y.; Wan, B.; Han, B.; Cai, G.; Chang, R. Strain and damage self-sensing of basalt fiber reinforced polymer laminates fabricated with carbon nanofibers/epoxy composites under tension. Compos. Part A Appl. Sci. Manuf. 2018, 113, 40-52. [CrossRef]

40. Esmaeili, A.; Sbarufatti, C.; Ma, D.; Manes, A.; Jiménez-Suárez, A.; Ureña, A.; Dellasega, D.; Hamouda, A. Strain and crack growth sensing capability of SWCNT reinforced epoxy in tensile and mode I fracture tests. Compos. Sci. Technol. 2020, 186, 107918. [CrossRef]

41. Tung, T.T.; Karunagaran, R.; Tran, D.N.H.; Gao, B.; Nag-Chowdhury, S.; Pillin, I.; Castro, M.; Feller, J.-F.; Losic, D. Engineering of graphene/epoxy nanocomposites with improved distribution of graphene nanosheets for advanced piezo-resistive mechanical sensing. J. Mater. Chem. C 2016, 4, 3422-3430. [CrossRef]

42. Chiacchiarelli, L.M.; Rallini, M.; Monti, M.; Puglia, D.; Kenny, J.M.; Torre, L. The role of irreversible and reversible phenomena in the piezoresistive behavior of graphene epoxy nanocomposites applied to structural health monitoring. Compos. Sci. Technol. 2013, 80, 73-79. [CrossRef]

43. Meeuw, H.; Viets, C.; Liebig, W.; Schulte, K.; Fiedler, B. Morphological influence of carbon nanofillers on the piezoresistive response of carbon nanoparticle/epoxy composites under mechanical load. Eur. Polym. J. 2016, 85, 198-210. [CrossRef]

44. Kanoun, O.; Benchirouf, A.; Sanli, A.; Bouhamed, A.; Bu, L. Potential of Flexible Carbon Nanotube Films for High Performance Strain and Pressure Sensors, One Central Press 148-183. Available online: https://www.researchgate.net/publication/28 1438116_Potential_of_Flexible_Carbon_Nanotube_Films_for_High_Performance_Strain_and_Pressure_Sensors (accessed on 19 February 2021).

45. Sanli, A.; Benchirouf, A.; Müller, C.; Kanoun, O. Piezoresistive performance characterization of strain sensitive multi-walled carbon nanotube-epoxy nanocomposites. Sens. Actuators A Phys. 2017, 254, 61-68. [CrossRef]

46. Bouhamed, A.; Müller, C.; Choura, S.; Kanoun, O. Processing and characterization of MWCNTs/epoxy nanocomposites thin films for strain sensing applications. Sens. Actuators A Phys. 2017, 257, 65-72. [CrossRef]

47. Sanli, A.; Müller, C.; Kanoun, O.; Elibol, C.; Wagner, M.F.-X. Piezoresistive characterization of multi-walled carbon nanotube-epoxy based flexible strain sensitive films by impedance spectroscopy. Compos. Sci. Technol. 2016, 122, 18-26. [CrossRef]

48. Michelis, F.; Bodelot, L.; Bonnassieux, Y.; Lebental, B. Highly reproducible, hysteresis-free, flexible strain sensors by inkjet printing of carbon nanotubes. Carbon 2015, 95, 1020-1026. [CrossRef]

49. Kaiyan, H.; Weifeng, Y.; Shuying, T.; Haidong, L. A fabrication process to make CNT/EP composite strain sensors. High Perform. Polym. 2017, 30, 224-229. [CrossRef]

50. Dai, H.; Thostenson, E.T.; Schumacher, T. Processing and Characterization of a Novel Distributed Strain Sensor Using Carbon Nanotube-Based Nonwoven Composites. Sensors 2015, 15, 17728-17747. [CrossRef]

51. Chou, T.-W. Microstructural Design of Fiber Composites; Cambridge University Press: Cambridge, UK, 1992.

52. Corum, J. Basic Properties of Reference Crossply Carbon-Fiber Composite. 2001. Available online: https://www.osti.gov/biblio/ 777662-basic-properties-reference-crossply-carbon-fiber-composite (accessed on 19 February 2021).

53. Morioka, K.; Tomita, Y. Effect of lay-up sequences on mechanical properties and fracture behavior of CFRP laminate composites. Mater. Charact. 2000, 45, 125-136. [CrossRef]

54. Hu, N.; Karube, Y.; Arai, M.; Watanabe, T.; Yan, C.; Li, Y.; Liu, Y.; Fukunaga, H. Investigation on sensitivity of a polymer/carbon nanotube composite strain sensor. Carbon 2010, 48, 680-687. [CrossRef] 